\title{
Study on Implementation of Defect Management Principle in Maintenance Practice at Local Authority
}

\author{
Ahmad Sharim Abdullah', Shahrul Yani Said, Lilis Shereena Safiee \\ ${ }^{1}$ Faculty of Architecture, Planning \& Surveying, Universiti Teknologi MARA, 40450 Shah Alam Selangor, Malaysia \\ sharim@uitm.edu.my, shahrulyani@uitm.edu.my, shereena0321@uitm.edu.my \\ Tel of 1st Author: +60104241563
}

\begin{abstract}
The purpose of this project is to develop processes for defect control in Malaysian public buildings. As a result, two objectives were established to achieve the goal: the study of defect management principles and analysis of defect management principles implementation levels in public building maintenance practises. Three local governments in the state of Selangor were the subjects of case studies. Using a systematic interview process, three building maintenance personnel were interviewed. Overall, the findings of this study revealed that each case study utilised defect management principles in a distinctive method. Despite the management and technical constraints, they are nevertheless able to manage the fault effectively.
\end{abstract}

Keywords: Building maintenance, defect management, public building, local authority

eISSN: 2398-4287C 2021. The Authors. Published for AMER ABRA cE-Bs by e-International Publishing House, Ltd., UK. This is an open access article under the CC BYNC-ND license (http://creativecommons.org/licenses/by-nc-nd/4.0/). Peer-review under responsibility of AMER (Association of Malaysian EnvironmentBehaviour Researchers), ABRA (Association of Behavioural Researchers on Asians/Africans/Arabians) and cE-Bs (Centre for Environment-Behaviour Studies), Faculty of Architecture, Planning \& Surveying, Universiti Teknologi MARA, Malaysia.

DOI: https://doi.org/10.21834/ebpj.v6iSI4.2919

\subsection{Introduction}

The government is looking more attention to maintenance and management issues at the public building to increase their reputation in delivering good services to the public (MA Backer, 2014). This can be achieved when it was managed effectively and efficiently when the organization stressed the importance of assets such as human, financial, and information resources (M. Mahli, 2012). However, there are many complaints and criticisms in media and research literature with the performance of public buildings in Malaysia on the lack of maintenance practice even though the government's consistent increase in maintenance expenditures specifically on preventing and repairing defects in the buildings. Although the main causes of defects in buildings are concerns with design detail, materials selection, workmanships, construction methods, regulations and rules and standards, a significant part of the defects are also caused by maintenance processes and procedures (A. Abdul Lateef Olanrewaju, 2012).

Although there are many systems related to maintenance management in public buildings, it still not consists of defect diagnosis for building and infrastructure to explain the real situation of the defect (Ismail \& Kasim, 2013). Many approaches have been applied to identify defect and defect management in the building maintenance process in the past. Hence, many studies on defect management systems have also been conducted to facilitate defect measures and rectifications and reduce the reoccurrence of the defect. However, those studies did not sufficiently consider the relationship of defect information flow in the maintenance process, which resulted in a reactive rather than proactive defect management plan. For the best defect management practice, a good

elSSN: 2398-4287@ 2021. The Authors. Published for AMER ABRA cE-Bs by e-International Publishing House, Ltd., UK. This is an open access article under the CC BYNC-ND license (http://creativecommons.org/licenses/by-nc-nd/4.0/). Peer-review under responsibility of AMER (Association of Malaysian EnvironmentBehaviour Researchers), ABRA (Association of Behavioural Researchers on Asians/Africans/Arabians) and cE-Bs (Centre for Environment-Behaviour Studies), Faculty of Architecture, Planning \& Surveying, Universiti Teknologi MARA, Malaysia.

DOI: https://doi.org/10.21834/ebpj.v6iSI4.2919 
technique on analysis of defect causation and its cost impact; the necessity of well-classified defect information; effective search and reuse of defect information and issues in defect management systems should be integrated through a systematic method considering the relationship of defect information flow in the maintenance process (Chan et al. 2013).

According to N. Forcada et al. (2010), Defect management is the process to manage and correct through quality inspection procedures. Kota (2010) also stated that a best defect management process is not only just complying with formal steps and procedures but specifically ensure that defects are being handled in a well-appropriate and organized manner from the time they are discovered till their resolution. In the defect managements principle, the process includes several stages. The stages are including defects prevention, delivery baseline, defect resolution, defect discovery and process development. The best approach to dealing with defects is to eliminate them. However, it is impossible with the current technology. That is why developers need to build up strategies to minimize the defects that occurred (Mosaic. Inc, 2002).

Alshehri (2015) mentioned in his article, there are several barriers to defect management practice in building maintenance. There are many issues on building maintenance, such as maintenance group management, performance, and execution of management during maintenance can be named as poor management of maintenance. The maintenance management team is a compelling device for accomplishing an exclusive requirement of maintenance work. Without this management and leadership of the organization, it will prompt tedious and failed maintenance works. The next barrier is an unqualified maintenance contractor. Public maintenance contracts are granted in light of a focused offering to secure the most reduced cost for maintenance operations. The project is regularly granted to the most minimal bidder gave. The minimum bidder will attempt to finish the work with the most minimal conceivable cost, keeping in mind the end goal to create a benefit from the venture. Other than that is for the third barrier is the poor quality of workmanship issues that are always related to small contractors as they are not well trained to be in the construction industries (Suffian, 2013).

\subsection{Result and Discussion}

Data collected from the interview survey were critically analyses to achieve the aim of this study which is to review the implementation level of the defect management in maintenance at the local authority. As mentioned above, the discussion of the results is emphasized in four parts: Part A is demographic, Part B is Implementation level of Defect Management in maintenance, which comprises Defect Prevention, Deliverable Baseline, Defect Discovery Defect Resolution, Process Improvement \& Management Reporting.

\section{Part A: Demographic Respondents}

This part of the interview requires respondents to complete the interview, consisting of demographics questions like name, age, title, department, organization, and experience in the company. All of the respondents are aged around 25 years until 40 years old. The respondents from LA1 have a lot an experience in charge of defect management that is ten years' experience, while the respondent from LA2 only has three years of working experience of the defect management team. They are also from different organizational departments, such as the engineering department and the building department.

\section{Part B: Implementation of Defect Management Principle in Maintenance.}

This section aims to identify the level of implementation of defect management principles in building maintenance practice.

\section{i) Defect Prevention}

\begin{tabular}{|l|l|l|l|l|}
\hline No & Implementation Level & \multicolumn{3}{|c|}{ Respondent } \\
\hline & & LA1 & LA2 & LA3 \\
\hline 1. & Identify critical risk assessment. & $\sqrt{ }$ & X & $\sqrt{ }$ \\
\hline 2. & Estimate expected impact & $\sqrt{ }$ & X & $\sqrt{ }$ \\
\hline 3. & Minimize expected impact & $\sqrt{ }$ & $\sqrt{ }$ & $\sqrt{ }$ \\
\hline
\end{tabular}

\section{Identify critical risk}

Identify risk is very important to reduce the outcome of the probability of the occurrence of the risk. Identify the types of defects that pose the most significant threat is the best approach for this part. There are two organizations (LA1 \& LA3) established in conducting the risk assessment by using specific tools such as Building Assessment Rating System (BARIS) developed by RISM. Meanwhile, for LA2, the critical risk assessment is determined through the examiner's experience, and there is an improper risk assessment conducted.

\section{Estimate expected impact}

Once the expected impact of each risk is identified, the risks should be prioritized by the impact and the level to which the expected impact can be minimized. For LA1 \& LA2, the expected impact is determined through experience and records from other projects or buildings. While LA3, the expected impact is calculating through analysis and determined from low to high.

Minimize expected impact 
Minimize expected impact is the action of reducing the risk. It involves the combination of the three strategies; eliminate risk, reduce the possibility of the risk becoming a problem, and reduce the impact of the problem that occurred. As expected for all organizations, remedial actions are taken in order to reduce that risk or eliminate it.

\section{ii) Deliverable Baseline}

\begin{tabular}{|l|l|l|l|l|}
\hline No & Implementation level & \multicolumn{3}{|c|}{ Respondent } \\
\hline & & LA1 & LA2 & LA3 \\
\hline 1. & Deliverable Baseline & $X$ & $X$ & $X$ \\
\hline
\end{tabular}

A deliverable (e.g. work product) is baselined when it reaches a predefined milestone in its development. This milestone involves transferring the product from one stage of development to the next. In all case studies, the deliverable baseline is not conducted in any work and projects as many as the organization does not recognize this concept.

iii) Defect discovery

\begin{tabular}{|l|l|l|l|l|}
\hline No & Implementation Level & \multicolumn{3}{|l|}{ Respondent } \\
\hline & & LA1 & LA2 & LA3 \\
\hline 1. & Defect finding & $\sqrt{ }$ & $\sqrt{ }$ & $\sqrt{ }$ \\
\hline 2. & Reporting the defect & $\sqrt{ }$ & $\sqrt{ }$ & $\sqrt{ }$ \\
\hline 3. & Defect acknowledgement & $\sqrt{ }$ & $\sqrt{ }$ & $\sqrt{ }$ \\
\hline
\end{tabular}

\section{Defect finding}

As for visual inspection done by LA1 \&LA2 are visually inspect the building where the defects can be found. The most common defects found during the visual inspection are staining and cracking. The whole structural inspection (LA3) may involve special tools such as moisture meter, infrared/thermographic camera and etc., to find the defects within the buildings. The best option to find a defect is through tools where causes of defects such as dampness and water content within a building can be found easily.

\section{Reporting the defect}

Once a defect discovered, the defect should be brought to management's attention. The defects can be reported by a simple written or electronic report. When a defect is initially uncovered, it may be very unclear whether it is a defect, a change, user error or a misunderstanding. In this case studies, all of the defect reporting are in a written form such as the site visit form and visual inspection report. It is important for management to know the occurrence of the defects so that they can be repaired as soon as possible.

\section{Defect acknowledgement}

When the defect has been brought to the attention of the management, the management must decide whether or not the defect is valid. When the defect is not reproducible and appears to be an isolated event, there will be an increased tendency for the management to assume the defect is invalid - that the defect is caused by user error or misunderstanding. In this case study, the defect has to be validated by an expert in the defect management department. Error in defects may cause implications and be costly; the defect has to be validated by an expert in the defect management department. Error in defects may cause implications and be costly.

\section{iv) Defect resolution}

\begin{tabular}{|l|l|l|l|l|}
\hline No & Implementation Level & \multicolumn{3}{|l|}{ Respondent } \\
\hline & & LA1 & LA2 & LA3 \\
\hline 1. & Defect Prioritize & $\sqrt{ }$ & $\sqrt{ }$ & $\sqrt{ }$ \\
\hline 2. & Schedule and Fix Defects & $\sqrt{ }$ & $\sqrt{ }$ & $\sqrt{ }$ \\
\hline 3. & Report Resolution & $\sqrt{ }$ & $\sqrt{ }$ & $\sqrt{ }$ \\
\hline
\end{tabular}

\section{Defect Prioritize}

A different approach has been applied to each case studies which is for LA1, it just severe or major building defects will be prioritised. For LA2, also prioritising urgent or safety involvement and only by report sequence for the common defect. For LA3, the higher score of defect rating will be highly prioritized and need serious attention. Emergency remedial work may be done immediately.

\section{Schedule and Fix Defects}

Commonly in order for remedial works are to be done by hired contractors, either they are annually contracted, in-house or outsource contractors (LA1, LA2 \&LA3). The work will be monitored by a supervisor so that the work done are according to the standards and 
completed within the time frame. When the task is done, the contractor may issue a letter of completion saying that the remedial works have been successfully completed.

\section{Report Resolution}

Once the defects have been remedied, all parties' concerns must be notified that the defects have been fixed along with other related information. As for all case studies, a maintenance work report is given and notified to all parties involved in the defects of the building.

\section{v) Process Improvement}

\begin{tabular}{|l|l|l|l|l|}
\hline No & Implementation Level & \multicolumn{3}{|l|}{ Respondent } \\
\hline & & LA1 & LA2 & LA3 \\
\hline 1. & Process Improvement & $\sqrt{ }$ & $\sqrt{ }$ & $\sqrt{ }$ \\
\hline
\end{tabular}

Process improvement is where to improve the current system to be more systematic and efficient. Defect itself may not completely be removed as to the deterioration of the building and also wear and tear by the user of the building. As for LA1, it stated that it needs to improve the current record system where now digitalized documents are much more convenient and easier. The same applies to LA2, where the need to implement the uses of a computerized system and digitalized documentation. As to LA3, stated that the building which may deteriorate and cause defects later would be avoided by implementing periodical maintenance and scheduled maintenance (e.g. painting to be renewed within five years, etc.)

\section{vi) Management Reporting}

\begin{tabular}{|l|l|l|l|l|}
\hline No & Implementation Level & \multicolumn{3}{|l|}{ Respondent } \\
\hline & & LA1 & LA2 & LA3 \\
\hline 1. & Management Reporting & $\sqrt{ }$ & $\sqrt{ }$ & $\sqrt{ }$ \\
\hline
\end{tabular}

It is important that the defect information, which is a natural by-product of the defect management process, be analyzed and communicated to the in-charge person and management. This could take the form of defect rates, defect trends, types of defects, failure costs, etc. As in LA 1 \& LA2, the management report is the Site Visit Form and Maintenance Work Report, which will be presented during their Committee Meeting. As for LA3, it has its own guidelines (Standard Building Condition Report). The report format includes inspection methodology, building condition Schedule, a summary of building condition, defect sheets and the building plan.

\subsection{Conclusion \& Recommendations}

This research focuses on the implementation level on defect management principle in the maintenance of public building practice by the selected local authority in Selangor. All three local authorities perform their practice in managing the defects in good practice. With the general guideline of defect management, it can see that there are some criteria that are not conducted, and some are conducted with their guidelines.

This research concludes that all the selected organizations need to strengthen further the defect management principle approach in maintaining the public building. Through this research study, the lack of implementation of good defect management principle practice might cause problems in the future. Therefore, a recommendation shall be made to cover the lacking part or improve the current practice in maintenance.

\section{Acknowledgements}

The authors would like to acknowledge the LESTARI Grant, Universiti Teknologi MARA, Project No: 600-RMI/DANA 5/3/LESTARI $(065 / 2017)$ for the financial support of this study.

\section{References}

Abdul Lateef Olanrewaju, (2012), "Quantitative analysis of defects in university buildings: user perspective", Built Environment Project anAsset Management, Vol. 2 Iss 2 pp. 167 - 181

Alshehri, A. R. (2015). Quality management system for building maintenance. Heriot-Watt University, School of Energy, Geosciences, Infrastructure and Society.

Chan-Sik Park, Do-Yeop Lee, Oh-Seong Kwon \& Xiangyu Wang, 2013, A framework for proactive construction defect management using BIM, augmented reality and ontology-based data collection template Automation in Construction 33 (2013) 61-71

Forcada, N., Margalida, E., Fuertes, A., Casals, M., Gangolells, M., Roca, X., \& Macarulla, (2010) M. A web-based system for quality inspection and defect management of industrial building construction. 
Ismail, Z., \& Kasim, N. (2013). 2013 Maintenance Management Practices for Building Maintenance: Case Studies. 2nd International Conference on Technology Management, Business and Entrepreneurship, (December), 5-17.

Kota, K. (2010). Defect Management. Management, 1-16.

MA Backer, M Ali, W Yusoff, W Zahari, 2014, A review of asset management practice in Malaysian local governments.

M. Mahli, A.I. Che-Ani, M.Z. Abd-Razak. N.M. Tawil, and H. Yahaya. (2012), "School-Age and Building Defects: AnalysisUsing Condition Survey Protocol (CSP) 1Matrix", World Academy of Science, engineering and technology, pp. 692.

Mosaic.Inc. (2002). Defect Management Process. Retrieved from http://www.defectmanagement.com/defectmanagement/modelmain.htm

Suffian, A. (2013). Some common maintenance problems and building defects: Our experiences. Procedia Engineering, 54, 101-108.

https://doi.org/10.1016/j.proeng.2013.03.009 